\title{
Quantitative Electrocardiographic Analysis in Relation to Renal Function in a Geriatric Population
}

\author{
Rodriguez-Padial L ${ }^{* 1}$, Akerström $\mathrm{F}^{1}$, Barderas $\mathrm{MG}^{2}$, Vivanco $\mathrm{F}^{3}$, Arias $\mathrm{MA}^{1}$, Mañas $\mathrm{LR}^{4}$, Ruilope $\mathrm{LM}^{5}$ and \\ Garcia-Garcia FJ ${ }^{6}$
}

${ }^{1}$ Department of Cardiology, Hospital Virgen de la Salud, Toledo, Spain

${ }^{2}$ Department of Vascular physiopathology, National Hospital of Paraplegics, Toledo, Spain

${ }^{3}$ Department of Immunology, IIS - Fundacion Jimenez Diaz, Madrid, Spain; Department of Biochemistry and

Molecular Biology I, University Complutense, Madrid, Spain

${ }^{4}$ Geriatrics Service, University Hospital of Getafe, Madrid, Spain

${ }^{5}$ Institute of Research and Hypertension Unit, Hospital 12 de Octubre, Madrid, Spain

${ }^{6}$ Hospital Virgen del Valle, Toledo Hospital Complex, Toledo, Spain

*Corresponding author: Rodríguez-Padial L, Department of Cardiology, Hospital Virgen de la Salud, Toledo, Spain, Fax: +34925269149, Tel: +34925269134, Email: lrodriguez@sescam.org

Citation: Rodriguez-Padial L, Akerström F, Barderas MG, Vivanco F, Arias MA, et al. (2015) Quantitative Electrocardiographic Analysis in Relation to Renal Function in a Geriatric Population. J Clin Exp Res Cardiol 2(3): 304. doi: 10.15744/2394-6504.2.304

Received Date: October 31, 2015 Accepted Date: November 26, 2015 Published Date: November 30, 2015

\begin{abstract}
Background: There is a frequent association between renal insufficiency and patients with cardiovascular disease, suggesting a common pathogenic mechanism. The electrocardiogram (ECG) is a quick and cheap tool that can detect early cardiac abnormalities. The aim of this study was to quantitatively analyze ECG alterations in relation to renal function of a population of 65 years or older.

Methods: A population sample of 1,536 patients aged 65 or older ( $45.4 \%$ male; mean age $75.6 \pm 6.0$ years) from the judicial district of Toledo, Spain, who had undergone a general medical checkup including an ECG were included. In 996 patients (64.8\%) renal function (plasma creatinine and estimated glomerular filtration rate) was assessed and the relationship between ECG alterations and renal function was subsequently evaluated.

Results: Only 36\% of the ECGs analyzed were considered normal. Significant correlations of heart rate, QRS complex duration, and the frontal plane QRS-T angle with reduced renal function were observed. Other ECG parameters such as voltage, QRS and T wave axes, and QTc interval showed no correlation with renal function.

Conclusions: In patients aged 65 years or older with impaired renal function there was a relationship of renal function with certain ECG parameters, which may constitute early markers of renal and cardiac pathology and suggest a common pathogenic mechanism.

Keywords: ECG; Renal function; Geriatric

List of abbreviations: Cr: Creatinine; ECG: Electrocardiogram; eGFR: Estimated Glomerular Filtration Rate; HTN: Hypertension; MDRD: Modification of Diet in Renal Disease; LVH: Left Ventricular Hypertrophy; RAAS: Renin-angiotensin-aldosterone System
\end{abstract}

\section{Introduction}

The cardiorenal syndrome illustrates the close relationship that exists between heart and kidney [1]. At the earliest phases of this pathological process there is a close interaction between both organs, which produces mutual progressive deterioration with loss of function through different pathological mechanisms, noticeably arterial hypertension (HTN) and renin-angiotensin-aldosterone system (RAAS) [2]. HTN is due to a complex pathophysiological process and can produce both cardiovascular [3] and renal diseases [4]. In the heart, HTN lead to coronary artery disease, left ventricular hypertrophy and dysfunction with grim prognosis [5]. Renal involvement is characterized by a progressive deterioration of glomerular filtration rate with or without albuminuria [4]. Furthermore, a higher degree of cardiac involvement is observed in patients with renal pathology and vice versa, [6-9] which suggests a common pathological mechanism, likely the RAAS [10]. Renal insufficiency is more prevalent in the elderly [11] who also commonly suffer from cardiovascular disease [12], and therefore old people constitute a suitable patient group to study the relationship between cardiac and renal diseases. 
The electrocardiogram (ECG) represents a quick, relatively cheap and readily available diagnostic tool, which has recently been found to improve risk stratification in the general population of age $\geq 65$ years $[13,14]$. The ECG has also been studied in patients with renal insufficiency [15,16] and microalbuminuria [17] and its alterations have been described previously. However, the relationship between ECG modifications and different degrees of renal failure has not been evaluated yet.

The Toledo Healthy Aging Study is a population based epidemiological study aimed at analyzing the different factors that lead to healthy aging. A comprehensive triennial assessment is carried out in a cohort of patients aged 65 years or over from Toledo (Spain), including a digital ECG recording and assessment of renal function $[18,19]$. This study quantitatively analyzed the digital ECG carried out at the first cross-section of the study (year 2006 to 2009) with the intention of evaluating the ECG alterations that occur with different degrees of renal function.

\section{Methods}

\section{Study group}

Data from the first cross-sectional study carried out in the Toledo Healthy Aging Study cohort [18,19] was used for this study. The original cohort consisted of 2,488 subjects of both sexes aged 65 years or over that were evaluated between June 2006 and September 2009. In 975 of these patients a digitalized ECG and simultaneous determination of creatinine were available. The study protocol was approved by the clinical ethics committee at Hospital Virgen de la Salud in Toledo and all individuals signed an informed consent.

To perform the analysis, patients were divided into several groups according to eGFR (1: $>90 ; 2: 60$ to $<90 ; 3: 30$ to $<60 ; 4: 15$ to $\left.<30 ; 5:<15 \mathrm{ml} / \mathrm{min} / 1.73 \mathrm{~m}^{2}\right)$, and $\operatorname{Cr}(1:<1 ; 2: 1$ to $<1.2 ; 3: 1.2$ to $<2.5 ; 4: 2.5$ to $<5 ; 5: \geq 5 \mathrm{mg} / \mathrm{dl})$.

\section{Electrocardiograms}

All patients underwent a standard 12-lead ECG with a MAC 1200 ST electrocardiograph (GE Medical Systems). All recordings were digitally stored in a GE Cardiosoft database (v. 6.5, GE Healthcare) and exported in XML format to the ELECTROPRES platform for computerized measurement and analysis. ELECTROPRESS is an on-line based platform aimed at early detection of left ventricular hypertrophy (LVH) by electrocardiography, which uses the Hannover ECG System (HES ${ }^{\circledR}$ program for ECG measurement and interpretation. This software, approved by the FDA, has shown a high accuracy in ECG interpretation [20,21], and has been evaluated in several clinical studies [22,23].

The study protocol of the ECG included: cardiac rhythm, heart rate, duration of waves and intervals (P, PR, QRS, QT), frontal plane axis (P, QRS, T) and amplitude, area and duration of Q, R and S waves of the 12 leads, as well as the morphologic diagnosis of the waves. The corrected QT interval (QTc) was calculated using the Bazett's formula. The QRS-T angle was determined as the absolute difference between the QRS complex and the T wave angles in the frontal plane (if the angle was $>180^{\circ}$, the difference between $360^{\circ}$ and the calculated angle was used so that the values used for the study were between 0 and $\pm 180^{\circ}$ ) [24].

\section{Renal function}

Renal function analysis was done at the laboratory of Hospital Virgen de la Salud in Toledo by measuring plasma creatinine (Cr, expressed as $\mathrm{mg} / \mathrm{ml}$ ) and calculating the estimated glomerular filtration rate (eGFR), using the modification of diet in renal disease (MDRD) formula (values expressed as $\mathrm{ml} / \mathrm{min} / 1.73 \mathrm{~m}^{2}$ ) [25].

\section{Statistical analysis}

Continuous variables are expressed as mean \pm standard deviation and qualitative variables as percentages. Subjects were classified into different categories depending on their age, as previously indicated. Comparisons between different groups were made with the Student $t$ test or analysis of variance, as appropriate. Linear regression was used to analyze association, with correction for pathologies (hypertension, coronary artery disease, heart failure, renal function) and drugs (digoxin, betablockers, antiarrhythmics). A significant level of $\mathrm{p}<0.05$ was considered. The calculations were performed using the statistical package Stata 12.1 .

\section{Results}

ECG was recorded in 1,536 patients of which 24 were excluded due to poor quality. The baseline characteristics are summarized in Table 1. Creatinine levels and eGFR were available in 965 patients, which constitute the study group.

The number of patients per predefined age group (1 to 4) was: 249 (16.5\%), 918 (60.7\%), 314 (20.7\%), and 31 (2.1\%), respectively. Mean Cr was $0.872 \pm 0.372 \mathrm{mg} / \mathrm{dl}$ and the number of patients per predefined Cr group (1 to 5) was: 696 (73.03\%), 146 (15.32\%), 107 (11.23\%), $3(0,31 \%)$, and $1(0,10 \%)$, respectively, for such reason groups 4 and 5 were combined. Mean eGFR was $28.84 \pm 34.78$ and number of patients per predefined GFR group (1 to 5) was: 39 (4.04\%), 219 (22.69\%), 144 (14.92\%), 9 (0.93\%), and 554 (57.41\%), respectively. 


\begin{tabular}{|c|c|}
\hline Parameter & \\
\hline Male, n (\%) & $686(45.4)$ \\
\hline Female, $\mathrm{n}(\%)$ & $826(54.6)$ \\
\hline Age, yr, mean (SD) & $75.62(5.96)$ \\
\hline$<70, \mathrm{n}(\%)$ & $249(16.5)$ \\
\hline 70-79, n (\%) & $918(60.7)$ \\
\hline $80-89, \mathrm{n}(\%)$ & $314(20.7)$ \\
\hline$\geq 90, \mathrm{n}(\%)$ & $31(2.1)$ \\
\hline Weight, kg, mean (SD) & $72.06(13.68)$ \\
\hline Height, m, mean (SD) & $157.40(8.98)$ \\
\hline BMI, kg/m², mean (SD) & $29.12(5.29)$ \\
\hline Systolic BP, mm Hg, mean (SD) & $144.95(32.14)$ \\
\hline Diastolic BP, mm Hg, mean (SD) & $76.54(17.05)$ \\
\hline Heart rate, bpm, mean (SD) & $69.35(11.14)$ \\
\hline Sodium, mEq/l, mean (SD) & $142.11(2.91)$ \\
\hline Potasium, mEq/l, mean (SD) & $4.49(0.43)$ \\
\hline Clorum, mEq/l, mean (SD) & $102.69(3.13)$ \\
\hline Calcium, mg/dl, mean (SD) & $9.37(0.53)$ \\
\hline \multicolumn{2}{|l|}{ Drug Treatment } \\
\hline Antihypertensives, n (\%) & $920(60)$ \\
\hline Lipid treatment, n (\%) & $534(35)$ \\
\hline Diuretics, n (\%) & $484(32)$ \\
\hline Diabetic treatment, n (\%) & $378(16)$ \\
\hline Antiplatelets, n (\%) & $337(32)$ \\
\hline Calcium channel blockers, n (\%) & $266(17)$ \\
\hline ACE inhibitors, n (\%) & $311(20)$ \\
\hline Angiotensin receptor blockers, $\mathrm{n}(\%)$ & $341(22)$ \\
\hline Antidepresants, n (\%) & $184(12)$ \\
\hline Betablockers, n (\%) & $158(10)$ \\
\hline Anticoagulants, $\mathrm{n}(\%)$ & $116(8)$ \\
\hline
\end{tabular}

Table 1: Baseline characteristics

A negative correlation between eGFR and age was observed $(P<0,001)$. The mean age of group 1 and 5 were $72.36 \pm 4.13$ years and $75.19 \pm 5.88$, respectively. Similarly, a positive correlation was observed between age and Cr (age group 1: 74.51 \pm 5.44 ; group 3: $77.36 \pm 6.25$; and group 4: $79.33 \pm 5.03$ years; $P<0,001)$.

\section{Electrocardiograms}

Considering the total population with available ECG recordings, these were considered normal in 544 (36\%) patients. Atrial fibrillation was present in 67 (4\%) and sinus arrhythmia in 118 (8\%) patients. In 27\% of the subjects LV hypertrophy was diagnosed using one or more of the established ECG criterion (Sokolow-Lyon voltage, Cornell voltage-duration product, and R wave in aVL). In 94 (6\%) and 23 (2\%) of the ECGs recordings ventricular and atrial premature contractions were observed, respectively. A prolonged PR interval was observed in 84 (6\%) and non-specific ST-T segment alterations were observed in 111 (7\%) of the ECG recordings. Furthermore, Q waves considered compatible with myocardial necrosis were noted in 81 (5\%) and Q waves that may be related to necrosis was observed in 271 (18\%) of the recordings. There were no statistically significant differences between the frequency of these ECG findings and renal function. A summary of the main ECG parameters can be observed in Table 2.

\section{Heart rate}

Heart rate was $69.35 \pm 11.14 \mathrm{bpm}$ (range $38-111 \mathrm{bpm}$ ). There was a significant increase in heart rate as the renal function deteriorates (heart rate Cr-group 1: $74.51 \pm 5.44 \mathrm{bpm}$ vs. Cr-group 4: $79.33 \pm 5.03 \mathrm{bpm} ; P<0.001$ ). A similar positive correlation between heart rate and eGFR was observed. Furthermore, when studying the relationship between heart rate with age and serum Cr, heart rate was independently correlated with $\mathrm{Cr}$ but not with age (heart rate $=-2.047458 \mathrm{x}$ serum $\mathrm{Cr}+66.83311 ; \mathrm{p}=0.032$ ). 


\begin{tabular}{|c|c|c|}
\hline Parameter & Mean \pm SD & Range \\
\hline Heart rate & $69.35 \pm 11.14 \mathrm{bpm}$ & $38-111 \mathrm{bpm}$ \\
\hline QRS axis & $6.84 \pm 39.36^{\circ}$ & $-91-179^{\circ}$ \\
\hline T wave axis & $38.58 \pm 39.08^{\circ}$ & $-98-178^{\circ}$ \\
\hline QRS-T wave angle & $19844.19 \pm 41.55^{\circ}$ & $0-180^{\circ}$ \\
\hline P wave & $108.22 \pm 13 \mathrm{~ms}$ & $66-180 \mathrm{~ms}$ \\
\hline QRS duration & $94.80 \pm 19.32 \mathrm{~ms}$ & $62-206 \mathrm{~ms}$ \\
\hline QTc interval & $425.8 \pm 24.39 \mathrm{~ms}$ & $347-542 \mathrm{~ms}$ \\
\hline
\end{tabular}

Table 2: Main ECG characteristics

\section{ECG voltage}

The eGFR showed a correlation with a minority of the QRS complex parameters (R-wave area in lead II, S-wave area in lead I and aVR, and Q-wave area in lead aVL). In addition, serum Cr was found to be correlated with some of the QRS complex parameters (Q-wave amplitude in I, V5, and V6; R-wave amplitude in V3; Q-wave area in I, aVR, and aVL; R-wave area in I and V1; and S-wave area in I, II, aVF and V1).

\section{Frontal plane QRS and T-wave axes, and QRS-T angle}

The mean frontal plane axes were: QRS 6.84 $\pm 39.36^{\circ}$ (range: $-91^{\circ}$ and $179^{\circ}$ ), T-wave $38.58 \pm 39.08^{\circ}$ (range: $-98^{\circ}$ and $178^{\circ}$ ), and QRS-T wave angle $44.19 \pm 41.55^{\circ}$ (range: $0^{\circ}$ and $180^{\circ}$ ). Neither the QRS axis $\left(6.71 \pm 38.88^{\circ}\right.$ in Cr-group 1 vs. $11.72 \pm 6.71^{\circ}$ in Cr-group 2 ; $P=0.087)$ nor the T-wave axis in the frontal plane were correlated with $\mathrm{Cr}$ or eGFR. Contrary, the QRS-T angle was significantly correlated with $\mathrm{Cr}$ (QRS-T angle $=20.34 \mathrm{Cr}+26.43 ; P<0.001)$. Furthermore, there were significant differences between the QRS- $\mathrm{T}$ angle in the different Cr levels (Cr-group 1: $41.63 \pm 40.44^{\circ}$; Cr-group 2: $49.72 \pm 42.86^{\circ}$; Cr-group 3: $51.08 \pm 46.91^{\circ}$; Cr-group 4 $68.00 \pm 65.19^{\circ}$ in group $\left.4 ; P=0.0013\right)$, whereas no differences of the QRS-T angle in the different eGFR groups were observed.

\section{$\mathrm{P}$-wave duration and PR interval}

The P-wave had a mean duration of $108.22 \pm 13 \mathrm{~ms}$ (range: 66-180ms) without significant differences between the different levels of Cr or eGFR groups. On the other hand, there was significant lengthening of the PR interval with a deterioration of renal function (Cr-group 1: $165.79 \pm 25.90 \mathrm{~ms}$ vs. Cr-group 3 and 4: $174.10 \pm 30.68 ; P<0.001$ ), although in the multiple regression analysis, the PR interval was more dependent on age $(P=0.048)$ than on serum Cr levels $(P=0.093)$.

\section{QRS duration and QTc interval}

Mean QRS complex duration was $94.80 \pm 19.32 \mathrm{~ms}$ (range: 62-206ms). There were significant variations in QRS duration with Cr groups (Cr-group 1: 92.55 $\pm 20.69 \mathrm{~ms}$; Cr-group 2: 94.04 \pm 28.13 ; Cr-group 3-5: $100.34 \pm 23.28 ; P<0.001$ ) but not with eGFR levels (Figure 1). In the multiple regression analysis, QRS complex duration was significantly correlated with $\mathrm{Cr}(\mathrm{QRS}$ duration=10.061 $\mathrm{x} \mathrm{Cr}+74.231 ; P<0.001)$, but not with age in this patient group $(P=0.258)$.

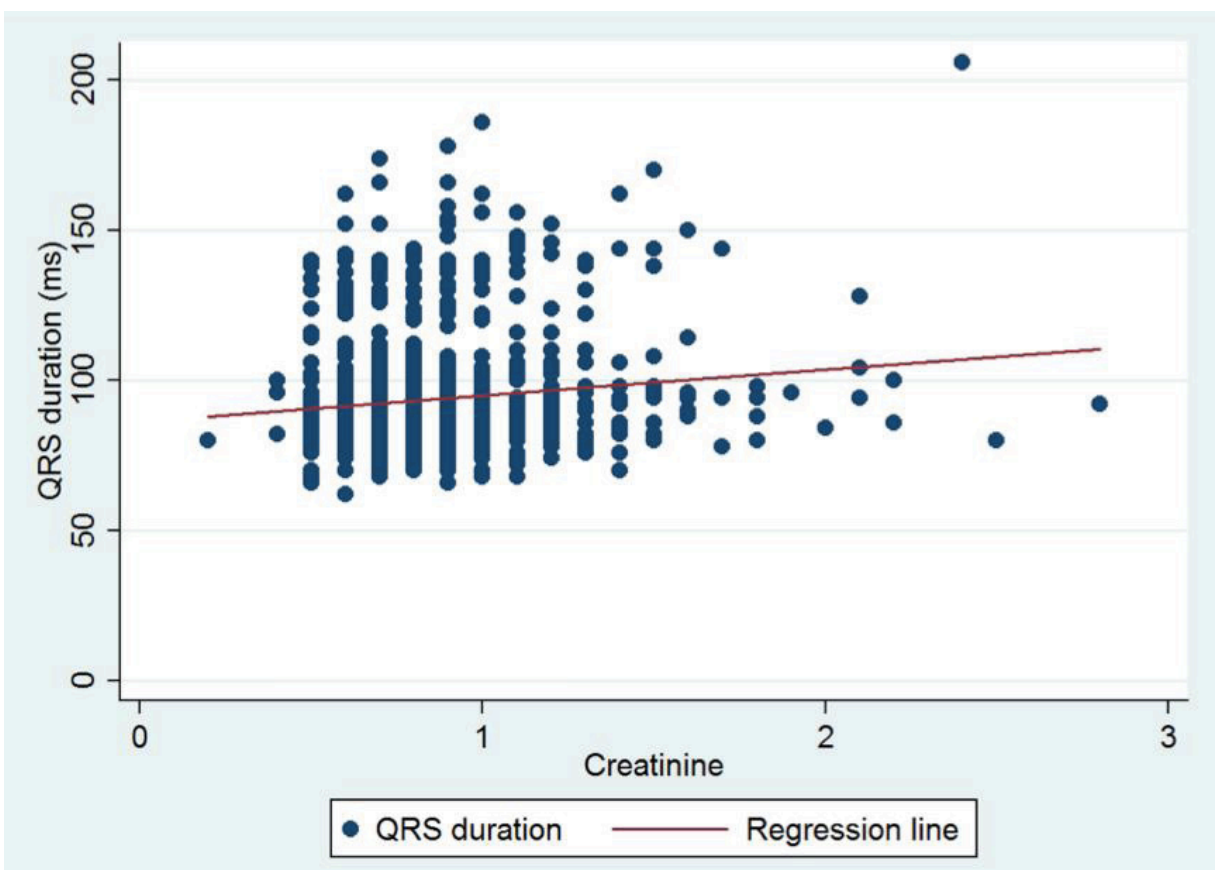

Figure 1: Regression analysis for QRS duration and creatinine showing a significant relationship between the two variables $(\mathrm{QRS}$ duration $=10.061 \mathrm{x} \mathrm{Cr}+74.231 ; P<0.001)$ 
The mean QTc interval was $425.8 \pm 24.39 \mathrm{~ms}$ (range $347-542 \mathrm{~ms}$ ) and there were no significant changes of this interval with Cr or eGFR.

\section{Discussion}

This study shows significant effects of deteriorating renal function on the ECG in the elderly, as it shows that renal function, as measured by plasmatic Cr or eGFR, was significantly correlated to some ECG parameters of proven prognostic value. In particular, worsening renal function was related to increased heart rate, QRS duration, and QRS-T angle in the frontal plane. Contrary, there was no significant relationship between renal function deterioration and changes in frontal plane QRS complex or T wave axes, amplitude of most of the ECG waves, P wave duration or QTc interval [26,27].

An independent association between ECG changes (rhythm, intraventricular conduction, and repolarization alterations) and microalbuminuria and chronic renal failure in hypertensive subjects has been described previously [15], emphasizing the existing relationship between cardiac and renal damage in this patient group. Moreover, in elderly patients an increased frequency of ECG alterations in renal failure has been reported and some of these ECG alterations have been linked to increased cardiovascular mortality and morbidity $[15,16]$, indicating their prognostic value. However, to the best of our knowledge there is no published data on the quantitative relationship between ECG alterations and renal function, which may be of relevance for the clinical evaluation of these patients.

Patients with renal insufficiency have an elevated risk of developing heart failure which is associated with some ECG alterations and worsening in prognosis [28]. The ECG alterations associated with worsening renal function as observed in this study, namely increased heart rate [29], QRS duration [30], and QRS-T angle [24,31], have all been correlated with a poor cardiovascular prognosis and the development of heart failure in different patient populations. Therefore, these ECG alterations may represent early markers of heart disease and an increased cardiovascular risk.

The observed association between a change in renal function and ECG alterations suggests a common pathogenetic pathway which could be the RAAS [10] as it is capable of producing damage in both organs. In fact, a relationship between aldosterone levels and deterioration of renal function in hypertensive patients has been described [32], and it has also been demonstrated that the inhibition of RAAS confers clinical benefits in patients with heart disease [33] and in those with chronic renal disease [34]. The association or ECG with renal function suggests that this quick and economic technique could be used as a marker of renal or cardio-renal disease, which could be of clinical importance.

This study has several limitations. This is a cross-sectional study, and therefore no prospective electrocardiographic data was available. Although the study sample is large, external validation is necessary in order to allow accurate extrapolation of the results. Furthermore, analysis of liver, pulmonary and brain status was carried out and this could theoretically have affected the ECGs of some of the study participants.

An important strength of this study is the use of computerized ECG interpretation, which is widely used in epidemiological studies, and has demonstrated high reliability and precision, avoiding the pitfalls of manual reading [35].

\section{Conclusion}

This study analyzed the electrocardiographic changes that occur in the elderly in relation to impaired renal function, which suggest that the ECG may represent a quick and easy technique to obtain marker of cardiovascular and renal risk in this growing patient group.

\section{Acknowledgements}

For the elaboration of this study LRP received grants PI031558, PI07/90637, PI07/90306, RD06/0013, PI11/01751, RD12/0043 (Institute of Health Carlos III, Ministry of Economy and Competitivity), 03031-00 (Institute of Health Sciences, Council of Health and Social Affairs of Castilla la Mancha), PI 11/01751 (FIS) and with support from the Cardiovascular Research Network (RIC) of the Institute of Health Carlos III.

\section{References}

1. Ronco C, Haapio M, House AA, Anavekar N, Bellomo R (2008) Cardiorenal syndrome. J Am Coll Cardiol 52: 1527-39.

2. Clementi A, Virzì GM, Goh CY, Cruz DN, Granata A, et al. (2013) Cardiorenal Syndrome Type 4: A Review. Cardiorenal Med 3: 63-70.

3. Kannel WB (1996) Blood pressure as cardiovascular risk factor: prevention and treatment. JAMA 275: 1571-6.

4. Chronic Kidney Disease Prognosis Consortium Matsushita K, van der Velde M, Astor BC, Woodward M, Levey AS, et al. (2010) Association of estimated glomerular filtration rate and albuminuria with all-cause and cardiovascular mortality in general population cohorts: a collaborative meta-analysis. Lancet 375 : 2073-81.

5. Vakili BA, Okin PM, Devereux RB (2001) Prognostic implications of left ventricular hypertrophy. Am Heart J 141: $334-41$.

6. Sciarretta S, Valenti V, Tocci G, Pontremoli R, Rosei EA, et al. (2010) Association of renal damage with cardiovascular diseases is independent of individual cardiovascular risk profile in hypertension: data from the Italy - Developing Education and awareness on MicroAlbuminuria in patients with hypertensive Disease study. J Hypertens 28: 251-8. 
7. Dinghra R, Gaziano JM, Djousse L (2011) Chronic kidney disease and the risk of heart failure in man. Circ Heart Fail 4: 138-44.

8. Wachtell K, Olsen MH, Dahlöf B, Devereux RB, Kjeldsen SE, et al. (2002) Microalbuminuria in hypertensive patients with electrocardiographic left ventricular hypertrophy: the LIFE study. J Hypertens 20: 405-12.

9. Cases Amenós A, González-Juanatey JR, Conthe Gutiérrez P, Matalí Gilarranz A, Garrido Costa C (2010) Prevalence of chronic kidney disease in patients with or at a high risk of cardiovascular disease. Rev Esp Cardiol 63: 225-8.

10. Drazner MH (2011) The progression of hypertensive heart disease. Circulation 123: 327-34.

11. Iseki K, Kinjo K, Iseki C, Takishita S (2004) Relationship between predicted creatinine clearance and proteinuria and the risk of developing ESRD in Okinawa, Japan. Am J Kidney Dis 44: 806-14

12. Rugale C, Du Cailar G, Fesler P, Ribstein J, Mourad G, et al. (2013) Effect of early stage kidney disease on cardiac mass: comparison to post-donation renal function. Am J Nephrol 38: 168-73.

13. Jorgensen PG, Jensen JS, Marott JL, Jensen GB, Appleyard M, et al. (2014) Electrocardiographic change improves risk prediction in asymptomatic persons aged 65 years or above without cardiovascular disease. J Am Coll Cardiol 64: 898-906.

14. Lauer MS (2014) Time to bring the "electrocardio-ome" into modern cardiovascular epidemiology? J Am Coll Cardiol 64: 907-9.

15. Kestenbaum B, Rudser KD, Shlipak MG, Fried LF, Newman AB, et al. (2007) Kidney function, electrocardiographic findings, and cardiovascular events among older adults. Clin J Am Soc Nephrol 2: 501-8.

16. Dobre M, Brateanu A, Rashidi A, Rahman M (2012) Electrocardiogram abnormalities and cardiovascular mortality in elderly patients with CKD. Clin J Am Soc Nephrol 7: 949-56.

17. Sciarretta S, Pontremoli R, Rosei EA, Ambrosioni E, Costa V, et al. (2009) Independent association of ECG abnormalities with microalbuminuria and renal damage in hypertensive patients without overt cardiovascular disease: data from Italy-Developing Education and awareness on microalbuminuria in patients with hypertensive Disease study. J Hypertens 27: 410-17.

18. García García FJ, Sánchez Ayala MI, Pérez Martín A, Martín Correa E, Marsal Alonso C, et al. (2001) Prevalencia de demencia y de sus tipos principales en sujetos mayores de 65 años: efecto de la educación y ocupación. Estudio Toledo. Med Clin (Barc) 116: 401-7.

19. Garcia-Garcia FJ, Gutierrez Avila G, Alfaro-Acha A, Amor Andres MS, De Los Angeles De La Torre Lanza M, et al. (2011) The prevalence of frailty syndrome in an older population from Spain. The Toledo Study for Healthy Aging. J Nutr Health Aging 15: 852-6.

20. Willems JL, Abreu-Lima C, Arnaud P, van Bemmel JH, Brohet C, et al. (1991) The diagnostic performance of computer programs for the interpretation of electrocardiograms. N Engl J Med 325: 1767-73.

21. Willems JL, Abreu-Lima C, Arnaud P, Brohet CR, Denis B, et al. (1990) Evaluation of ECG interpretation results obtained by computer and cardiologists. Methods Inf Med 29: 308-16.

22. Rodríguez-Padial L, Rodríguez-Picón B, Jerez-Valero M, Casares-Medrano J, Akerström FO, et al. (2012) Precisión diagnóstica del electrocardiograma asistido por ordenador al diagnosticar hipertrofia ventricular izquierda en el bloqueo de rama izquierda. Rev Esp Cardiol 65: 38-46.

23. Rodríguez-Padial L, Akerström F, Robles-Gamboa C, Andrés J, Ruiz-Baena J (2013) Diagnostic accuracy of left ventricular hypertrophy in patients with myocardial infarction by computer-assisted electrocardiography (ELECTROPRES). Ann Noninvasive Electrocardiol 18: 170-80.

24. Walsh JA 3rd, Soliman EZ, Ilkhanoff L, Ning H, Liu K, et al. (2013) Prognostic Value of Frontal QRS-T Angle in Patients Without Clinical Evidence of Cardiovascular Disease (from the Multi-Ethnic Study of Atherosclerosis). Am J Cardiol 112: 1880-4.

25. Levey AS, Coresh J, Balk E, Kausz AT, Levin A, et al. (2003) National Kidney Foundation. National Kidney Foundation practice guidelines for chronic kidney disease: evaluation, classification, and stratification. Ann Intern Med 139: 137-47.

26. National Kidney Foundation (2002) K/DOQI clinical practice guidelines for chronic kidney disease: evaluation, classification, and stratification. Am J Kidney 39: S1-266.

27. Rodríguez-Padial L, Robles C, García-García FJ. El electrocardiograma en el paciente geriátrico. Análisis cuantitativo en una muestra poblacional de pacientes mayores de 65 años (Estudio Toledo de Envejecimiento Saludable). In press Falta la revista

28. Smith GL, Lichtman JH, Bracken MB, Shlipak MG, Phillips CO, et al. (2006) Renal impairment and outcomes in heart failure: systematic review and metaanalysis. J Am Coll Cardiol 47: 1987-96.

29. Ekelund LG, Haskell WL, Johnson JL, Whaley FS, Criqui MH, et al. (1988) Physical fitness as a predictor of cardiovascular mortality in asymptomatic North American men. The Lipid Research Clinics Mortality Follow-up Study. N Engl J Med 319: 1379-84.

30. Badheka AO, Singh V, Patel NJ, Deshmukh A, Shah N, et al. (2013) QRS duration on electrocardiography and cardiovascular mortality (from the National Health and Nutrition Examination Survey-III). Am J Cardiol 112: 671-7.

31. Aro AL, Huikuri HV, Tikkanen JT, Junttila MJ, Rissanen HA, et al. (2012) QRS-T angle as a predictor of sudden cardiac death in a middle-aged general population. Europace 14: 872-6.

32. Roldán J, Morillas P, Castillo J, Andrade H, Guillén S, et al. (2010) Plasma aldosterone and glomerular filtration in hypertensive patients with preserved renal function. Rev Esp Cardiol 63: 103-6.

33. Dahlöf B, Devereux RB, Kjeldsen SE, Julius S, Beevers G, et al. (2002) Cardiovascular morbidity and mortality in the Losartan Intervention For Endpoint reduction in hypertension study (LIFE): a randomised trial against atenolol. Lancet 359: 995-1003.

34. Kunz R, Friedrich C, Wolbers M, Mann JF (2008) Meta-analysis: effect of monotherapy and combination therapy with inhibitors of the renin angiotensin system on proteinuria in renal disease. Ann Intern Med 148: 30-48.

35. Kors JA, van Herpen G (2012) Computer analysis of the electrocardiogram. En: Macfarlane PW, van Oosterom A, Janse M, Kligfield P, Camm J, Pahlm O, editores. Specialized aspects of ECG. London: Springer Verlag 303-42. 


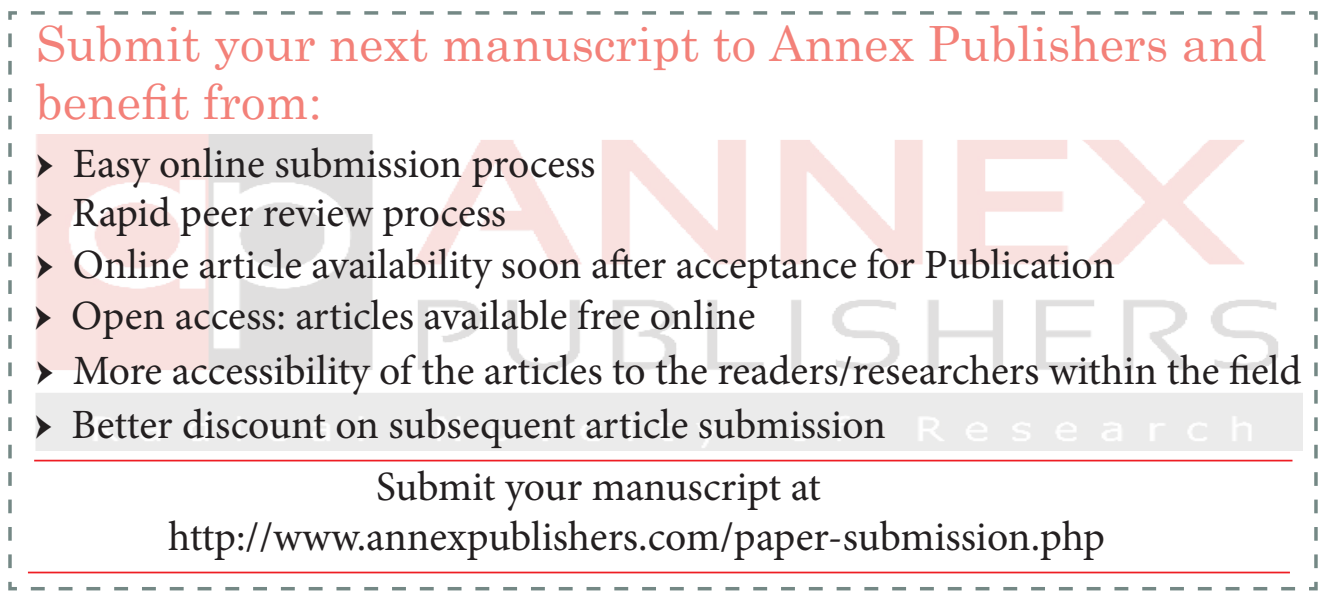

